\title{
Choice of approaches for surgical correction of tricuspid pathology in patients with
} rheumatic multi-valvular heart disease

\author{
Hamidullah A. Abdumadzhidov, Hayrullah J., Buranov, Ilkhom K. Huzhakulov, Ikrom I. \\ Mirhodzhaev, Sh.T. Artikov \\ Republican Specialized Center of Surgery named after academician V. Vahidov, Tashkent, \\ Uzbekistan
}

\begin{abstract}
Objective: To analyze the results of surgical correction of patients with tricuspid pathology in rheumatic multi-valvular heart disease.

Methods: We retrospectively analyzed outcomes of surgical correction of tricuspid valve disease in 292 patients with rheumatic multi-valvular heart defects, who underwent surgery in our clinic.

Results: The age of our patients ranged from 12 to 74 years (mean age 36.7 (9.4) years), among them 197 (67.4\%) women and 95 (32.6\%) - men. According to the degree of circulatory disorders, $21(7.2 \%)$ patients were in NYHA class III and $271(92.8 \%)$ patients - class IV. Of them $235(80.5 \%)$ patients were operated by the method of De Vega using plastic fibrous ring. After tricuspid valve (TV) and fibrous ring repair in $26.9 \%$ - tricuspid regurgitation disappeared, in $62.8 \%$ - regurgitation decreased to the $1^{\text {st }}$ degree, and the remaining $10.3 \%$ of patients had $2^{\text {nd }}$ (moderate) degree tricuspid regurgitation. In 7 (2.38\%) cases of infective endocarditis, the "open heart surgery" correction - replacement of TV with biological prosthesis was made. Creation of the bicuspid tricuspid valve techniques was used in $13.4 \%$ of cases.

Conclusion: Our study demonstrated that correction of tricuspid valve disease in our cohort of patients, including valve repair and replacement and reconstructive surgery of fibrous ring alone or in combination with mitral or aortic valve replacement/ repair is accompanied by reduction of tricuspid regurgitation and reduction of cardiac chamber size and right ventricular pressure. No complications intrinsic to operative technique of tricuspid valve reconstructive surgery as advanced atrioventricular block or myocardial ischemia and infarction were recorded.
\end{abstract}

Key words: tricuspid heart disease, multivalvular heart disease, tricuspid valve repair, De Vega fibrous ring

(Heart Vessels and Transplantation 2017; 1: doi: 10.24969/2017.9)

\section{Introduction}

According to statistics, the cause of the multivalve heart disease is often a rheumatism, accounting for $60-65 \%$ of cases of combined valve heart pathology (1-7). Based on data from the statistics in our country about 14,000-15,000 patients are in need of surgical correction of acquired heart diseases per year, of whom half are diagnosed with multi-valve heart defects $(2,4,6$, 7).

During recent decades surgical management of multi-valve heart defects has improved and attained desirable outcomes. This is facilitated by the improvement of methods of diagnostics and 
surgical tactics, the development of different ways of reconstructive operations, the improvement of anesthesia and improved methods to protect the myocardium and postoperative management of this difficult group of patients. In patients with multi-valve heart disease, it is difficult to resolve the issue - whether correcting accompanying moderate malformation of the tricuspid valve (TV) or use conservative management tactics, the latter as experience shows, is justified only when there are hemodynamically insignificant lesions of the TV $(1,3,5)$. Thus, the defect correction of tricuspid disease as well as correction of other components of a complex multi-valve rheumatic heart disease is important in achieving good immediate and late results of operations.

We aimed to analyze the results of TV surgery in patients with multi-valve heart disease, who underwent surgical correction in our clinic.

\section{Methods}

We analyzed data of 3277 patients with acquired heart defects underwent surgical correction under extracorporeal circulation (EC) with cardioplegia (CP) at the Department of Reconstructive Surgery for the period of 10 years, and $292(8 \%)$ of them underwent TV disease correction.

For diagnosis of multi-valve acquired heart disease in addition to general clinical examination, we used invasive, non-invasive methods of diagnosis: electrocardiography, transthoracic (TTE) and transesophageal echocardiography (TEE) with Doppler echocardiography, chest XRay, computed tomography (CT), heart catheterization with coronary angiography and aortography. We assessed echocardiographically the percentage of change in TV regurgitation and hemodynamics, cardiac chamber size before and after operations.

The surgical correction of multivalve heart disease with involvement of TV included following types of operations: replacement of native with prosthetic valve - aortic valve replacement (AVR), mitral valve replacement (MVR), and tricuspid valve replacement (TVR), mitral valve repair (MV repair), aortic valve repair (AV repair), tricuspid valve repair (TV repair).
We used descriptive statistics to analyze data. Data are presented as mean (SD) and number (percentage) and t-test for dependent samples to compare continuous data before and after surgery.

\section{Results and discussion}

The age of our patients ranged from 12 to 74 years (mean age 36.7(9.4) years), among them 197 (67.4\%) women and 95 (32.6\%) - men. According to the degree of circulatory disorders, $21(7.2 \%)$ patients were in NYHA class III and $271(92.8 \%)$ patients in NYHA functional class IV (Table 1).

\begin{tabular}{|c|c|c|}
\hline Variables & & $\begin{array}{l}\text { Table 1. Clinical characteristics of patient } \\
\text { who underwent tricuspid valve surgery }\end{array}$ \\
\hline \multicolumn{3}{|l|}{ Sex } \\
\hline Men & 95 & 32.6 \\
\hline Women & 197 & 67.4 \\
\hline \multicolumn{3}{|l|}{ NYHA class } \\
\hline III & 21 & 7.2 \\
\hline IV & 271 & 92.8 \\
\hline Total & 292 & $100 \%)$ \\
\hline
\end{tabular}

According to the analysis of clinical material and the results of the executed corrections can show the following: our patients had predominantly TV regurgitation associated with mitral valve disease, due to congestion of the pulmonary circulation, and partly as a compensatory response to progressive pulmonary hypertension. Isolated tricuspid valve disease occurs, as we know, rarely and among our patients, we had less than $4 \%$ of patients who needed replacement of TV.

By etiological causes, TV disease is associated with rheumatism, followed by infective endocarditis, degenerative valve changes, specific infections and trauma. In our practice, the most frequent causes were rheumatism and infective endocarditis.

Based on the above diagnostic methods, in 292 cases $(8 \%)$ with TV disease and multivalve heart defects, surgical correction was performed including valve replacement or repair, or combined with correction of multivalve heart disease performed in conditions of open heart 
surgery. In our patients, we performed several types of TV correction, including open tricuspid commissurotomy (OTC) with correction of fibrous ring and TV replacement. Surgical correction in our patients was performed under EC and CP. The types of the surgical corrections of mutli-valve disease, with TV involvement are presented in Table 2.

\section{Table 2. The types of interventions for multi- valve disease with tricuspid valve involvement}

\begin{tabular}{|c|c|c|}
\hline Type of surgery & $\mathbf{n}$ & $\%$ \\
\hline AVR, MVR with TV repair & 148 & 50.68 \\
\hline $\begin{array}{l}\text { TV repair with MV repair and AV } \\
\text { repair }\end{array}$ & 52 & 17.81 \\
\hline $\begin{array}{l}\text { MVR with TV repair and AV } \\
\text { repair }\end{array}$ & 41 & 14.04 \\
\hline MVR with TV repair & 16 & 5.48 \\
\hline $\begin{array}{l}\text { AVR with TV repair and AV } \\
\text { repair }\end{array}$ & 13 & 4.45 \\
\hline AVR, MVR with OTVC & 8 & 2.74 \\
\hline MVR, TVR & 4 & 1.37 \\
\hline MVR, TVR, and AVR & 3 & 1.02 \\
\hline Other Operations & 7 & 2.39 \\
\hline Total operations & 292 & 100 \\
\hline
\end{tabular}

More than half of patients underwent TV repair along with AVR and MVR, repair of TV, MV and AV was performed in $17.81 \%$ of patients, MVR with TV repair and AV repair was performed in $14 \%$ of patients, MVR with TV repair in $5.48 \%$ of patients, AVR with TV repair and MV repair in $4.45 \%$ MVR with TV repair and AV repair, AVR and MVR with tricuspid commissurotomy in $2.74 \%$ of patients, and in few patients TVR was performed accompanying MVR $-1.37 \%$ and AVR and MVR in $1.02 \%$ of patients. Thus, the most frequent type of surgery was multivalvular intervention - mitral and aortic valve replacement with TV repair.

Reconstructive valve and ring surgery in this group of patients has grown in recent years. As we know, TV pathology develops according to distinctive scenario: if the fibrous ring (FR) expands, tricuspid stenosis develops in the frontal direction and tricuspid valve cusps remain intact, mostly septal cusp. The vegetation's in infective endocarditis grow in the same direction. This creates the need to apply so-called reinforcement of FR portions unlike the mitral valve. In addition, heart failure and pulmonary hypertension $(\mathrm{PH})$ play an important role in development of highdegree TV regurgitation. As practice and our observations show, the need for correction of high-degree TV regurgitation specifies mandatory monitoring of regression of $\mathrm{PH}$. If necessary, it is better to leave a small degree of regurgitation, as early postoperative overcorrection of TV leads to the development of right heart failure. In view of this, we tend to choose a correction in the form of annuloplasty of TV fibrous ring, sometimes in combination with an open tricuspid commissurotomy with repair of FR. There are several types of annuloplasty of fibrous ring and TV repair developed by Kay and De Vega, and modifications of these techniques (8-12). 
In our clinic, the most commonly used reconstructive surgery for TV FR was by De Vega method. Such corrections were performed in $235(80.5 \%)$ cases. Among these 235 patients, who was received valve repair by method of De Vega in $26.9 \%$ of patients regurgitation practically disappeared after surgery, in $62.8 \%$ - regurgitation decreased to minimum (1 degree) and in $10.3 \%$ reduced to $2^{\text {nd }}$ degree. Double pure suturing of the fibrous ring of $\mathrm{TV}$ was performed using Ethibond 2/0 or Prolene 2/0-3/0. Monitoring of the adequacy of repair was done with aid of an occluder with a diameter of $35 \mathrm{~mm}$ (for women), and up to $40 \mathrm{~mm}$ (for men). Sometimes we applied finger method to control adequacy of TV FR. The result was visually monitored and using water sample. In $8(2.7 \%)$ cases of the combined tricuspid valve stenosis and regurgitation, we additionally performed open commissurotomy and repair of fibrous ring. When annulodilatation was unsuccessful, annuloplasty of FR on a support ring was performed, we used CarpentierEdwards ring only 3 (1.02\%) (Fig. 1).

\begin{tabular}{|l|c|}
\hline \multicolumn{2}{|l|}{$\begin{array}{l}\text { Table 3. Percentage of postoperative } \\
\text { regurgitation changes }\end{array}$} \\
\hline Regurgitation degree & Percentage \\
\hline Practically disappeared & $26.9 \%$ \\
\hline $\begin{array}{l}\text { Decrease to } 1^{\text {st }} \text { degree } \\
\text { (minimal) }\end{array}$ & $62.8 \%$ \\
\hline $\begin{array}{l}\text { Reduced to } 2^{\text {nd }} \text { degree } \\
\text { (moderate) }\end{array}$ & $10.3 \%$ \\
\hline
\end{tabular}

Previously widely used method of creating a bicuspid TV by method of Kay et al. (8-10). The latter technique was performed in $13.4 \%$ cases. This applied "U" shaped seam on both sides with FR on the pads with bringing closer ends, creates a bicuspid valve and reduces regurgitation. Unfortunately, in recent years, this technique is used less frequently due to low efficacy compared to the method of De Vega $(11,12)$.

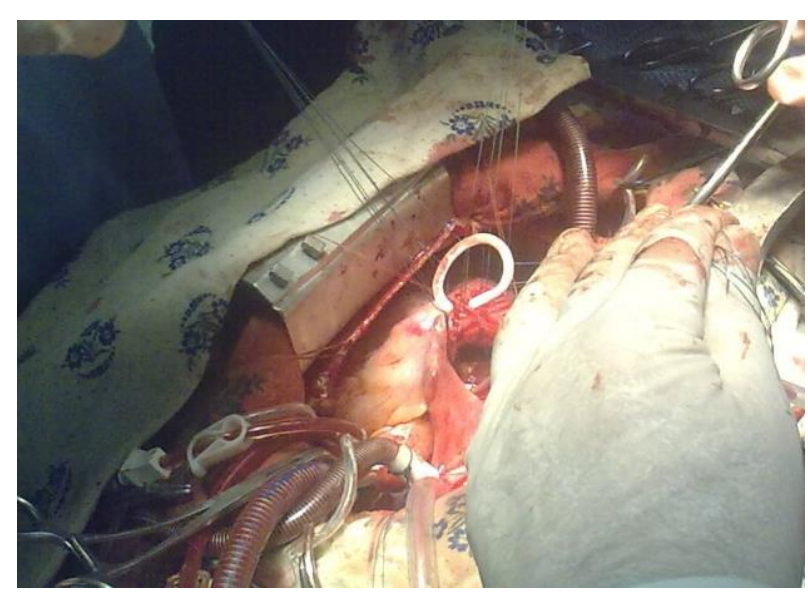

Figure 1. Intraoperative view of TV annuloplasty with support rings

To prevent the development of some postoperative complications, one needs to navigate the surgical anatomy of the anteriorseptal commissure, where the bundle of His is situated, to avoid development of a complete atrio-ventricular block. Also, lying sulcus coronaries extends right coronary artery trunk in the frontal cusp zone (3-4mm from FR) and commissures in the area of the side and caution should be applied not to damage coronary artery and cause complication like myocardial ischemia and infarction. The process of stitching on the fibrous ring of plastic is made with strict regard to the anatomy of the conduction system and the right coronary artery. Our patients did not have such complications in form of atrio-ventricular block or myocardial ischemia and infarction. 

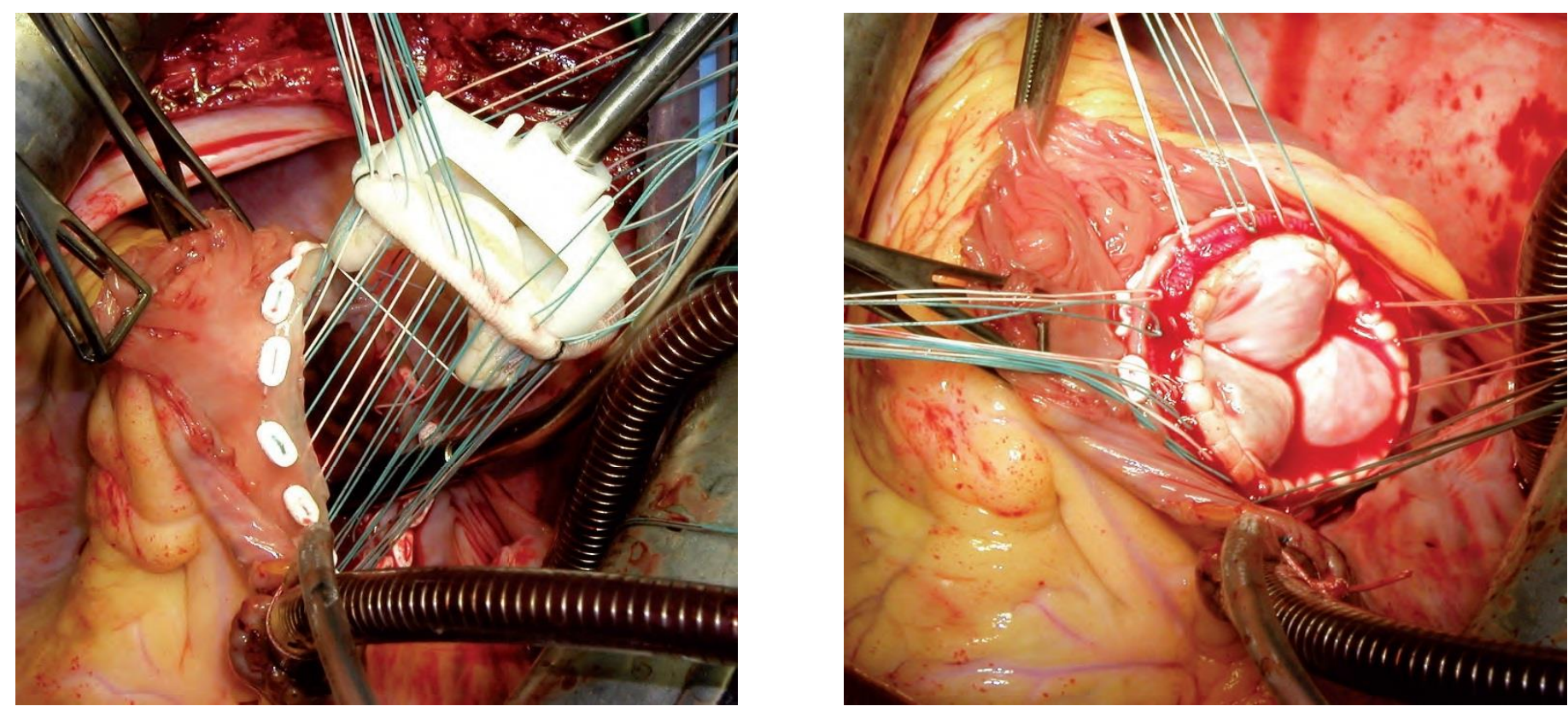

Figure 2. Intraoperative view of tricuspid valve replacement with biological prosthesis by St. Jude method

\begin{tabular}{|c|c|c|c|}
\hline Variables & Before the operation & After the operation & $\mathbf{p}$ \\
\hline End-diastolic size, $\mathbf{m m}$ & $75.5(2.7)$ & $62.9(2.3)$ & $<0.01$ \\
\hline End-systolic size, $\mathbf{m m}$ & $57.1(2.2)$ & $47.6(1.9)$ & $<0.05$ \\
\hline End-diastolic volume, ml & $240.3(24.5)$ & $180.3(20.5)$ & $>0.05$ \\
\hline End -systolic volume, ml & $122.5(12.2)$ & $95.1(10.2)$ & $>0.05$ \\
\hline Stroke volume, ml & $120.5(12.3)$ & $85.4(10.2)$ & $>0.05$ \\
\hline Ejection fraction (\%) & $58.1(2.3)$ & $48.4(1.9)$ & $>0.05$ \\
\hline $\begin{array}{c}\text { Right ventricular pressure, } \\
\text { mmHg }\end{array}$ & $65.5(2.7$ & $45.9(2.3)$ & $>0.05$ \\
\hline Left atrial size, $\mathrm{mm}$ & $67.1(2.2)$ & $47.6(1.9)$ & $>0.05$ \\
\hline
\end{tabular}


Multivalve correction of acquired heart disease usually require long-term of EC and occlusion of the aorta, and the use of methods of surgical correction of the TV disease under EC condition on a beating heart with aortic occlusion reduces time and improves multivalve heart defects surgery results compared to the "open" heart surgery. In our clinic, we used this technique in patients with isolated and combined TV disease. In 12 cases out of 292, we have applied TV repair with surgery on mitral and/or aortic valve, among them in 10 cases - we performed annuloplasty of FR with reconstruction, and in 2 cases - TVR with biological prosthesis. In these cases, after the phase of correction of mitral and / or aortic valves, atrial septum was sealed. After the prevention of air embolism and rewarming the patient to 36-37 degrees, we removed the clip from the aorta. After the restoration of cardiac function, we performed TV repair on a beating heart. After checking the adequacy of the correction of the tricuspid valve, continued operation of the standard protocol. TVR in our practice was performed in $7(2.38 \%)$ patients. All patients were operated on for infectious endocarditis as a cause of TV disease.

Along with the general clinical research methods, to assess the results of surgical correction of pathologies multivalve correction tricuspid component contact transthoracic echocardiography is widely used in the early and late periods. As can be seen from Table 4 we observed a significant reduction of left ventricular and left atrial dimensions and tendency to decrease in right ventricular pressure in our patients who underwent reconstructive surgery on $\mathrm{TV}$ alone or in combination with mitral or aortic valve surgeries.

Thus, the choice of tactics of surgical correction of the TP is defined on the basis of the established degree of disease (stenosis or in combination) of the valve, the morphological status of the valves, subvalvular structures valve apparatus and the presence of pulmonary hypertension.

\section{Study Limitations}

Our study has limitation intrinsic to the design of the study.

\section{Conclusion}

Our study demonstrated that correction of tricuspid valve disease in our cohort of patients, including valve repair and replacement and reconstructive surgery of fibrous ring alone or in combination with mitral or aortic valve replacement/ repair is accompanied by reduction of tricuspid regurgitation and reduction of cardiac chamber size and right ventricular pressure. No complications intrinsic to operative technique of tricuspid valve reconstructive surgery as advanced atrioventricular block or myocardial ischemia and infarction were recorded.

Peer-review: Internal and external

Conflict of interest: None to declare

Authorship: H.A.A., H.J.B., I.K.H., I.I.M,

S.T.A.

\section{References}

1. Bokeria LA, Stupakov IN, Samorodskaya IV. The incidence and the need for cardiac treatment methods in the aspect of epidemiological analysis. Thorac Cardiovasc Surg 2006; 1: 4-7 [Russian].

2. Bokeria LA, Stupakov IN, Gudkov RG. Surgery of acquired heart disease in Russia. Proceedings of XIIIth All-Russian Congress of Cardiovascular Surgeons. Moscow 25-28, November 2007. Bulletin NTSSSH named by akad. Bakulev RAMS. 2007; 8: 36 (Abstract) [Russian].

3. Hamzayev AB, Dobrotin SS, Pichugin VV, et al. Surgical technique for the correction of multi-valve heart defect. Pathology of the 
Circulatory and Cardiac Surgery 2006; 4: 21-5 [Russian].

4. Dzemeshkevich SL, Stevenson LW Diseases of the mitral valve. Moscow, GEOTAR "Medicine". 2000. 299s.

5. Semenov MD, Sokolov VV, Kovalev AI, et al. Direct results of three simultaneous prosthetic heart valves. Thorac Cardiovasc Surg 2006; 1: 14-9 [Russian].

6. Skopin II, Mironenko VA Abdyvasiev KA, et al. Long-term results of mitral valve replacement with reconstruction of subvalvular structures EPTFE thread. Proceedings of the First Congress of Cardiovascular Surgeons of Central Asia. (Bishkek. 14-15 September, 2007) Kyrgyzstan. Medicine. 2007; 4: 133-42. 7. Duedener LF, Wendler O, Nikoloudakis N, George T, Fries R, Schafers HJ. Mitral valve repair without annuloplasty rings: results after repair of anterior leaflet versus posterior leaflet defects using politetrafluoroethylene sutures for chordal replacement. Eur J CardioThoracic Surg 2000; 17: 206-12.
8. Kay GL, Morita S, Mendez M, Zubiate P, Kay JH. Tricuspid regurgitation associated with mitral valve disease: repair and replacement. Ann Thorac Surg 1989: 48 (3 Suppl): S93-5.

9. Kay JH, Mendez AM, Zubiate P. A further look at tricuspid annuloplasty. Ann Thorac Surg 1976: 22; 498-500.

10. Kay JH, Maselli-Campagna G, Tsuji KK. Surgical treatment of tricuspid insufficiency. Ann Surg 1965; 162: 53-8.

11. De Vega NG. La annuloplastia selective, regulable y permanente. Una tecnica original para el tratamiento de la insuficienca tricuspide. Selective, adjustable, and permanent annulolasty. An original technic for the treatment of tricuspid insufficiency. Rev Esp Cardiol 1972; 25: 555-6.

12. Rabago G, De Vega NG, Castillon L, Moreno T, Fraile J, Azpitarte J, et al. The new De Vega technique in tricuspid annuloplasty (results in 150 patients). J Cardiovasc Surg (Torino) 1980; 21: 231-8. 